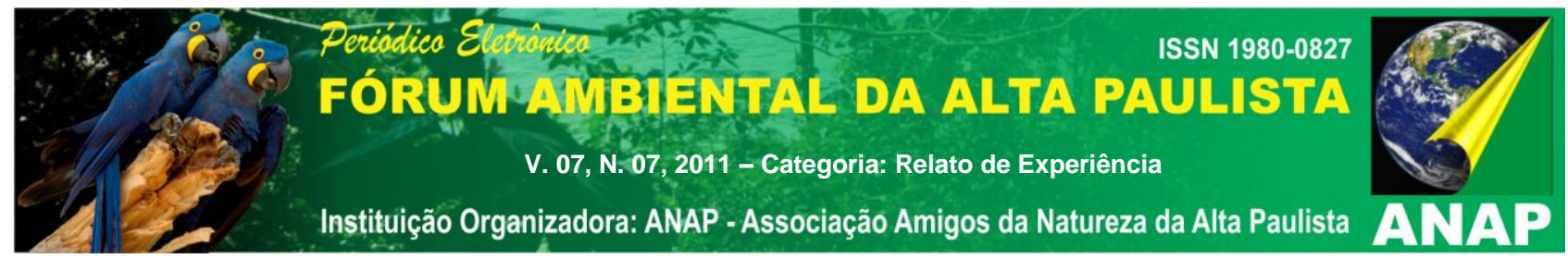

Titulo do Trabalho

\title{
UTILIZAÇÃO DE SISTEMAS DE INFORMAÇÕES GEOGRÁFICAS NA ANÁLISE DE PROPOSTAS DE LOCALIZAÇÃO DE RESERVA LEGAL
}

Nome do Autor Principal

Egberto da Fonseca Casazza

Nomes dos Co-autores

Guilherme Casoni da Rocha, Paulo Guilherme Rigonatti e Cristina Maria do Amaral Azevedo

Instituição ou Empresa

Secretaria de Meio Ambiente do Estado de São Paulo

E-mail de contato

guilhermecr@ambiente.sp.gov.br

RESUMO: No Brasil um dos instrumentos utilizados para garantir a conservação da biodiversidade em propriedades rurais particulares é a reserva legal. Este estudo de caso demonstra a avaliação das propostas de localização de reserva legal pela Secretaria de Meio Ambiente, que passa por uma análise de documentos dos proprietários e das propriedades envolvidas na proposta e, quando necessário, depende da realização de vistorias presenciais das propriedades por técnicos da Secretaria de Meio Ambiente. $O$ objetivo do trabalho foi aperfeiçoar a análise das propostas de averbação de reserva legal recebidas pela Secretaria do Meio Ambiente do Estado de São Paulo por meio da utilização de Sistemas de Informações Geográficas. Visando disponibilizar as informações cartográficas, a todos os servidores da Secretaria de Meio Ambiente executores das análises de propostas de localização de reserva legal foi criado no software ArcGis 9.3.1 (ESRI) um mapa digital contendo diversos planos de informações (layers) para ser visualizado no software ArcGIS Explorer (ESRI). Alem de a celeridade conferida à análise também deve ser destacada a confiabilidade conferida à análise do processo, uma vez que de posse de informações cartográficas produzidas a partir de fontes rastreáveis e métodos conhecidos torna-se possível atestar a correção das informações apresentadas pelo interessado. A criação de uma ferramenta para auxiliar a análise das propostas de localização de reserva legal proporcionou um grande ganho de eficiência para a SMA. 


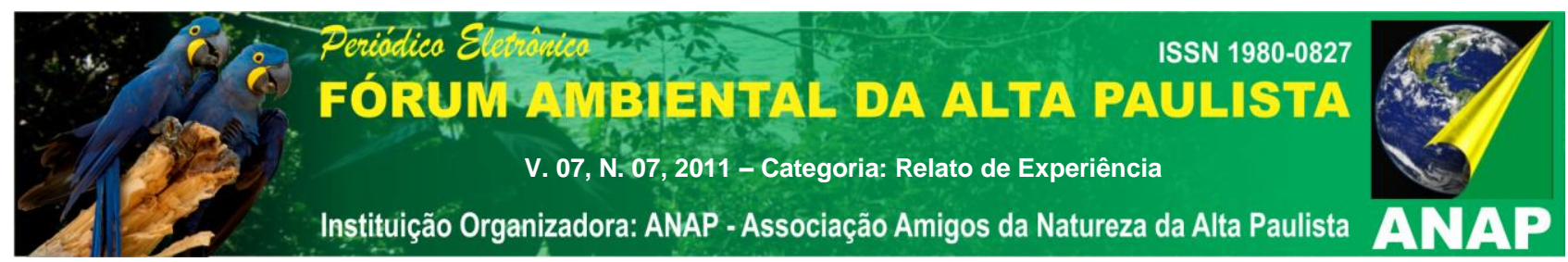

Palavras chave: Reserva legal, Código Florestal, Sistemas de Informações Geográficas

\section{INTRODUÇÃO}

No Brasil um dos instrumentos utilizados para garantir a conservação da biodiversidade em propriedades rurais particulares é a reserva legal ${ }^{1}$ (Brasil, 1965). O objetivo inicial desse mecanismo foi a da manutenção de uma área mínima para fornecimento de recursos florestais, tais como madeira, lenha e carvão, além de possibilitar a exploração dos recursos em longo prazo em áreas ainda não desmatadas (Ranieri, 2004).

No estado de São Paulo as áreas que devem ser mantidas a título de reserva legal devem ocupar no mínimo $20 \%$ da área total da propriedade rural. Ainda de acordo com o Código Florestal a localização da reserva legal deve ser aprovada pelo órgão competente ou, mediante convênio, pelo órgão ambiental municipal ou outra instituição devidamente habilitada. No caso do estado de São Paulo quem exerce esta atribuição é a Secretaria de Estado de Meio Ambiente (SMA). Diversos critérios devem ser seguidos durante a análise da localização da reserva legal, tais como: o plano de bacia hidrográfica, o plano diretor municipal, o zoneamento ecológico-econômico, outras categorias de zoneamento ambiental; a proximidade com outra reserva legal, área de preservação permanente, unidade de conservação ou outra área legalmente protegida; existência de fragmentos florestais na propriedade entre outras.

O Decreto Estadual 53939/2009 (São Paulo, 2009) dispõe sobre a manutenção, recomposição, condução da regeneração natural, compensação e composição da área de Reserva Legal de imóveis rurais no Estado de São Paulo, além de estabelecer os critérios que devem orientar a aprovação da localização dessa área pelo órgão competente. 0 decreto paulista inclui, nessa análise, a utilização do mapa de Áreas Prioritárias para o

\footnotetext{
1 Reserva Legal: área localizada no interior de uma propriedade ou posse rural, excetuada a de preservação permanente, necessária ao uso sustentável dos recursos naturais, à conservação e reabilitação dos processos ecológicos, à conservação da biodiversidade e ao abrigo e proteção de fauna e flora nativas (definição segundo Código Florestal).
} 


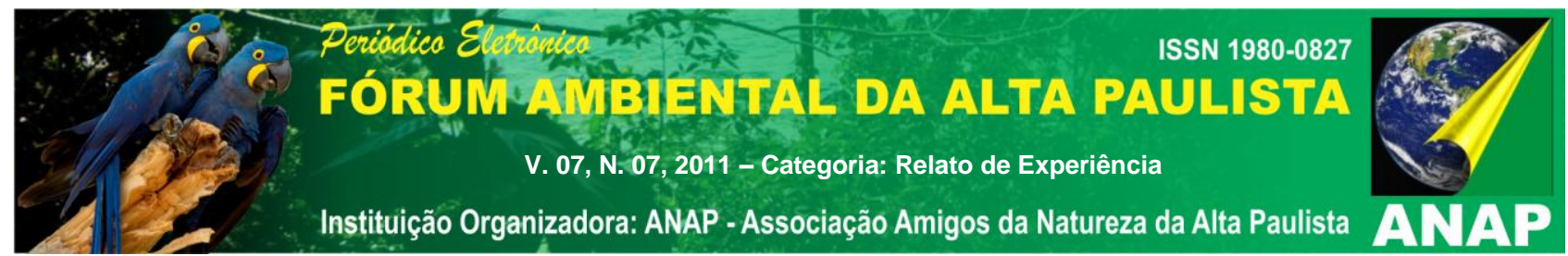

Incremento de Conectividade elaborado no âmbito do Projeto Diretrizes para a Conservação e Restauração da Biodiversidade no Estado de São Paulo (Programa BIOTA/FAPESP, 2007).

A avaliação das propostas de localização de reserva legal pela Secretaria de Meio Ambiente, passa por uma análise de documentos dos proprietários e das propriedades envolvidas na proposta e, quando necessário, depende da realização de vistorias presenciais das propriedades por técnicos da Secretaria de Meio Ambiente.

Quando protocolados os documentos na Secretaria de Meio Ambiente, estes passam a fazer parte de um processo. O processo é instruído com a documentação entregue pelo interessado (planta da propriedade, documentos de comprovação de posse, memoriais descritivos das áreas envolvidas, laudos de vegetação, dentre outros). A análise das plantas e seu conteúdo (demarcação de área da vegetação nativa, áreas especialmente protegidas, corpos d'água, caminhos, estradas, edificações existentes e a construir e confrontantes, entre outros) em conjunto com as vistorias é a etapa da análise do processo que mais demanda tempo dos técnicos da SMA, uma vez que são necessários consultas a diversas fontes de informações geográficas, acessadas somente por técnicos capacitados em sistemas de informações geográficas (SIG).

Após analise e posterior aprovação das propostas apresentadas, são emitidos termos de responsabilidade de preservação de reserva legal, que são assinados tanto pelos proprietários, ou seus representantes legais, quanto pela autoridade ambiental. Esses termos possibilitam a averbação à margem da matrícula do imóvel no registro de imóveis competente, conforme determinação do Código Florestal e do Decreto estadual $539329 / 08$.

\section{OBJETIVO GERAL}




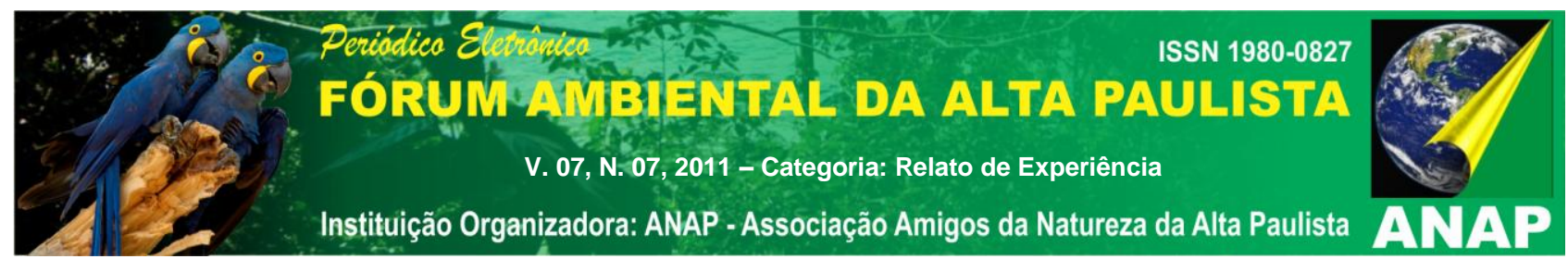

O objetivo do trabalho foi aperfeiçoar a análise das propostas de averbação de reserva legal recebidas pela Secretaria do Meio Ambiente do Estado de São Paulo por meio da utilização de Sistemas de Informações Geográficas.

\section{OBJETIVOS ESPECÍFICOS}

- Reduzir tempo de análise das propostas de averbação de reserva legal;

- Aumentar o número de informações agregadas à análise da proposta de averbação de reserva legal, consequentemente diminuindo as incertezas técnicas do processo;

- Reduzir o número de vistorias realizadas pelos técnicos da SMA;

- Reduzir o custo para a SMA da análise das propostas de averbação de reserva legal;

- Uniformizar a análise realizada pelos técnicos da SMA das propostas de averbação de reserva legal.

\section{METODOLOGIA}

Visando disponibilizar as informações cartográficas, antes restritas aos técnicos operadores de Sistemas de Informações Geográficas (SIGs), a todos os servidores da Secretaria de Meio Ambiente executores das análises de propostas de localização de reserva legal foi criado no software ArcGis 9.3.1 (ESRI) um mapa digital contendo diversos planos de informações (layers) para ser visualizado no software ArcGIS Explorer (ESRI).

Este mapa foi criado no formato layer package (.lpk) e continha as seguintes informações cartográficas: Municípios do Estado de São Paulo (IGC), Unidades de Gerenciamento de Recursos Hídricos do Estado de São Paulo (IGC), Articulação das 


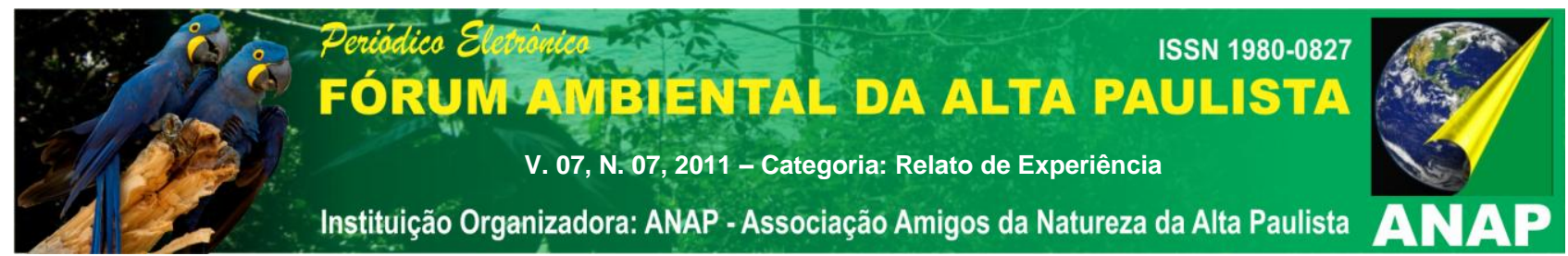

Cartas do Mapeamento Sistemático (IBGE) escala 1:50.000; Articulação das cartas do Sistema Cartográfico Metropolitano (EMPLASA) escala 1:10000; Articulação das Imagens do Satélite CBERS 2; Inventário Florestal da Vegetação Nativa do Estado de São Paulo (Instituto Florestal); Mapa de Biomas do Brasil (IBGE) Mapa de Vegetação do Brasil (IBGE); Mapa das Áreas Prioritárias para o Incremento da Conectividade da Biodiversidade (BIOTA/FAPESP) e áreas protegidas do Estado de São Paulo (organizadas por técnicos da SMA).

A opção pela utilização do software ArcGis 9.3.1 para criação do mapa deveu-se ao fato de a possibilidade de criar arquivos no formato layer package enquanto a escolha do software ArcGiS Explorer baseou-se nos seguintes critérios: gratuidade do software; facilidade de operação e interface amigável e leitura de arquivos no formato layer package. Os dois softwares utilizados no processo de otimização da análise das propostas de localização de reserva legal são produzidas pela empresa canadense ESRI sendo que o primeiro possui funções de edição e criação de informações geográficas o segundo permite apenas a visualização destas informações.

O formato de arquivo layer package foi o que possibilitou a utilização de Sistemas de Informações Geográficas por todos os técnicos da Secretaria de Meio Ambiente, uma vez que este formato gera arquivos de tamanho reduzido e conta com um layout permanente. $\mathrm{O}$ tamanho reduzido do arquivo exige pouca capacidade de processamento dos computadores utilizados pelos executores das análises e o layout permanente evita a necessidade de os usuários realizarem consultas complexas dentro do SIG, tornando mais simples a visualização e extração de informações cartográficas do sistema.

A facilidade na leitura das informações cartográficas e a interface amigável do software ArcGis Explorer associadas à sua baixa exigência de capacidade de processamento das máquinas e ao seu caráter gratuito permitiu a utilização imediata da ferramenta pelos técnicos da Secretaria de Meio Ambiente, uma vez que dispensou necessidade de realização de treinamentos longos e a aquisição de equipamentos, agilizando e isentando de custos adicionais para a administração pública o processo de adoção da tecnologia. 


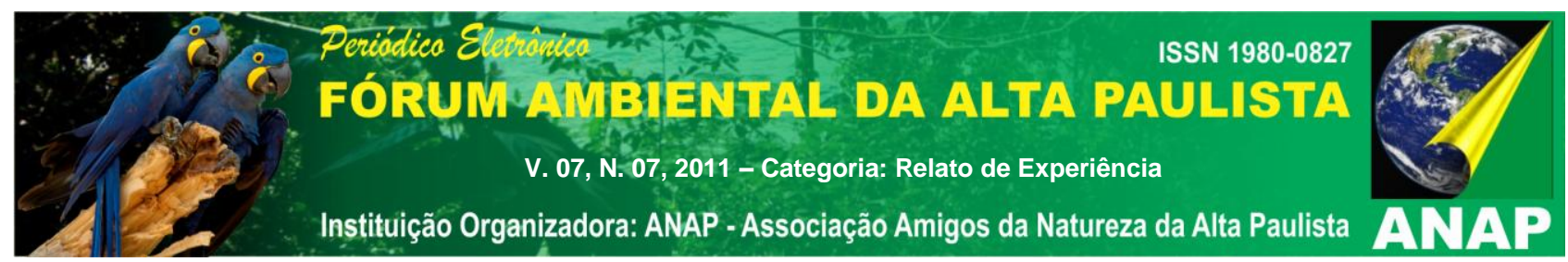

O mapa criado foi disponibilizado para os executores das análises de propostas de localização de reserva legal e o software foi instalado nas estações de trabalho destes técnicos. Também foi criado para o mesmo, acesso ao banco de dados geográficos da SMA, a partir do qual seria possível acessar imagens digitalizadas e georreferenciadas das cartas do mapeamento sistemático do IBGE na escala 1:50000, imagens digitalizadas e georreferenciadas das cartas do Sistema Cartográfico Metropolitano da Emplasa na escala de 1:10.000 e imagens do satélite CBERS 2 com resolução espacial de 20m.

Uma vez disponibilizados os mapas, o software e o acesso ao banco de dados da SMA foi realizado um breve treinamento com objetivo de demonstrar o método de análise das propostas de averbação de reserva legal por meio de SIG. O treinamento foi ministrado pelos técnicos que desenvolveram a ferramenta e teve duração aproximada de seis horas. Neste treinamento foram apresentados o software e suas funções, as informações contidas no mapa, o procedimento de análise bem como o método de acesso ao banco de dados. Como complementação ao treinamento foram realizadas análises conjuntas envolvendo instrutores e técnicos de processos de averbação de reserva legal utilizando o SIG desenvolvido.

\section{RESULTADOS}

Após o desenvolvimento do SIG e o treinamento dos técnicos da SMA as análises das propostas de localização de reserva legal feitas na coordenadoria passaram a ser avaliadas pelos seguintes aspectos:

- Localização da propriedade quanto a município, UGRHI e bacia hidrográfica;

- Existência de corpos hídricos, e consequentemente Áreas de Preservação Permanente dentro da propriedade; 


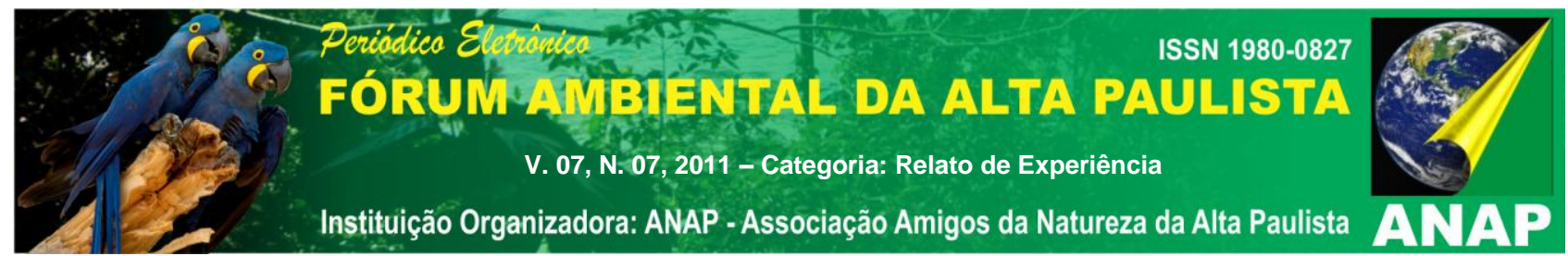

- Existência de remanescentes florestais de vegetação nativa dentro da propriedade;

- Bioma no qual está inserida a propriedade

- Formação vegetal que cobre a propriedade

- Importância da área para o incremento da conectividade da biodiversidade;

A avaliação da localização da propriedade quanto ao município, UGRHI e bacia hidrográfica são realizadas utilizando as informações contidas no próprio mapa criado para ser visualizado no ArcGis Explorer com base nas informações de localização da(s) propriedade(s) inseridas na proposta pelo proprietário.

A existência de corpos hídricos e de Áreas de Preservação Permanente ${ }^{2}$ dentro da propriedade é verificada por meio da análise das cartas do mapeamento sistemático do IBGE 1:50000 e das cartas do Sistema Cartográfico Metropolitano. Estas cartas são visualizadas no próprio ArcGis Explorer e são armazenadas no banco de dados da SMA. As cartas a serem analisadas são selecionadas por meio das camadas de articulação contidas no mapa criado.

A presença de remanescentes florestais nas propriedades é avaliada mediante a visualização do Inventário dos Remanescentes Florestal da Vegetação Nativa do Estado de São Paulo. Este documento é uma camada do mapa criado e sua análise é complementada pela visualização das imagens do satélite CBERS 2 realizadas no software ArcGis Explorer, armazenadas no banco de dados da Coordenadoria e selecionadas por meio das camadas de articulação contidas no mapa.

O bioma no qual estão inseridas as propriedades, bem como a formação vegetal que as recobrem, são informações analisadas por meio de duas camadas produzidas a partir de material elaborado pelo IBGE. As duas informações em questão são

\footnotetext{
${ }^{2}$ Área de preservação permanente: área protegida nos termos dos arts. $2^{\circ}$ e $3^{\circ}$ desta Lei, coberta ou não por vegetação nativa, com a função ambiental de preservar os recursos hídricos, a paisagem, a estabilidade geológica, a biodiversidade, o fluxo gênico de fauna e flora, proteger o solo e assegurar o bem estar das populações humanas (definição segundo Código Florestal).
} 


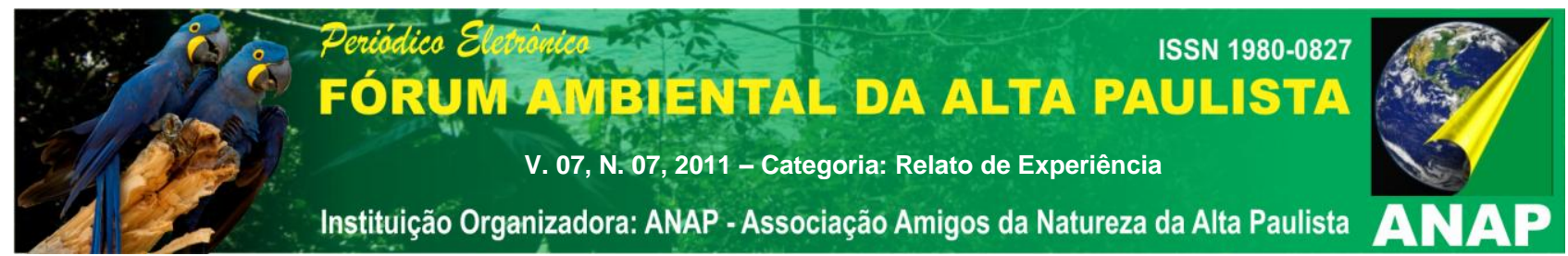

corroboradas por dados oriundos do Inventário Florestal da Vegetação Nativa do Estado de São Paulo, uma vez que neste documento também é informada a classificação fitofisionômica dos remanescentes florestais.

A prioridade da área para o incremento da conectividade da biodiversidade é avaliada pelo Mapa das Áreas Prioritárias para o Incremento da Conectividade da Biodiversidade, sendo este também uma camada do mapa criado.

As áreas protegidas também formam uma camada do mapa possível de ser visualizada diretamente no ArcGis Explorer. Esta informação torna-se de extrema importância para análise do processo de localização de reserva legal já que manter áreas cobertas de vegetação nativa livres do risco de perturbações antropogênicas mais significativas próximas a outras áreas protegidas é sempre muito benéfico do ponto de vista da conservação da biodiversidade.

A avaliação de todos os aspectos listados acima durante o processo de análise de averbação de reserva lega é bastante célere, uma vez que todas consultas às informações ambientais necessárias são realizadas instantaneamente pelo próprio técnico que faz a análise em sua estação de trabalho. $O$ fato da maior parte das informações estarem contidas no mapa criado, sendo acessadas sem a necessidade de consultas mais complexas dentro do ambiente SIG ou por meio do tráfego em rede de informações armazenadas em servidores externos ou na própria internet também contribui de maneira decisiva para acelerar o processo de análise.

Alem de a celeridade conferida à análise também deve ser destacada a confiabilidade conferida à análise do processo, uma vez que de posse de informações cartográficas produzidas a partir de fontes rastreáveis e métodos conhecidos torna-se possível atestar a correção das informações apresentadas pelo interessado. $O$ fato de contar com uma grande gama de informações para análise das propostas de averbação de reserva legal, somado à possibilidade de confrontar as informações fornecidas pelos interessados tornou a instrução da análise mais completa, possibilitando o pleno atendimento da legislação e proporcionando que a reserva legal tenha um impacto mais significativo no meio biofísico. 


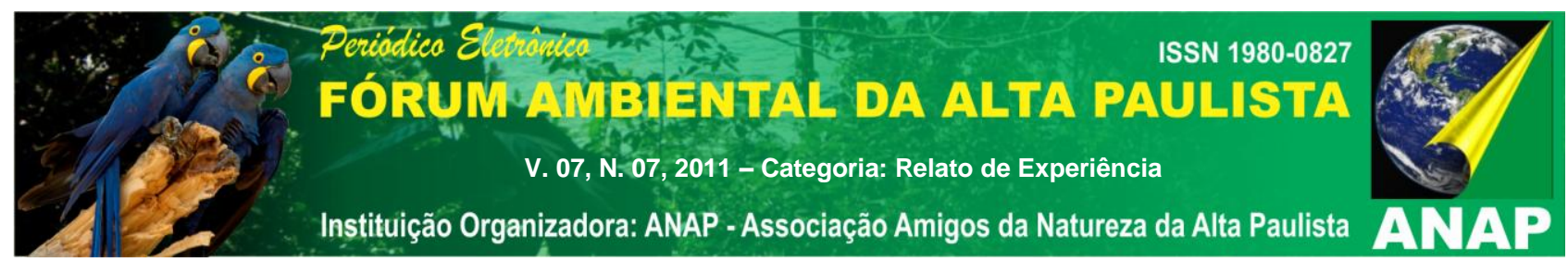

\section{CONSIDERAÇÕES FINAIS}

A criação de uma ferramenta para auxiliar a análise das propostas de localização de reserva legal proporcionou um grande ganho de eficiência para a SMA, uma vez que reduziu as horas técnicas empregadas nesta atividade e aumentou a qualidade dos resultados do trabalho. Ainda faltam avaliações mais descritivas do impacto de tal ferramenta no cotidiano da referida coordenadoria, principalmente no que se refere ao tempo total de tramitação da proposta de averbação dentro da SMA.

Por fim vale lembrar que a adoção de uma nova ferramenta baseada em SIG para auxiliar nas análises de propostas de averbação de reserva legal criam dois trabalhos adicionais para coordenadoria, caso esta queira seguir aproveitando dos ganhos de eficiência por esta proporcionado, quais sejam: atualização constante das informações cartográficas e das imagens de satélite contidos nos mapas e treinamento continuado aos técnicos que utilizam e gerenciam a ferramenta, uma vez que um recurso empregador de tanta tecnologia como este tende a necessitar constantemente de atualizações para ser utilizado em sua plenitude.

\section{REFERÊNCIAS}

BRASIL. Lei n 4.771, de 15 de setembro de 1965. Institui o novo Código Florestal.

SÃO PAULO. Decreto Estadual 53939, de 7 de janeiro de 2009. Dispõe sobre a manutenção, recomposição, condução da regeneração natural, compensação e composição da área de Reserva Legal de imóveis rurais no Estado de São Paulo.

RANIERI, V.E.L. Reservas Legais: Critérios para Localização e Aspectos de Gestão. Tese 


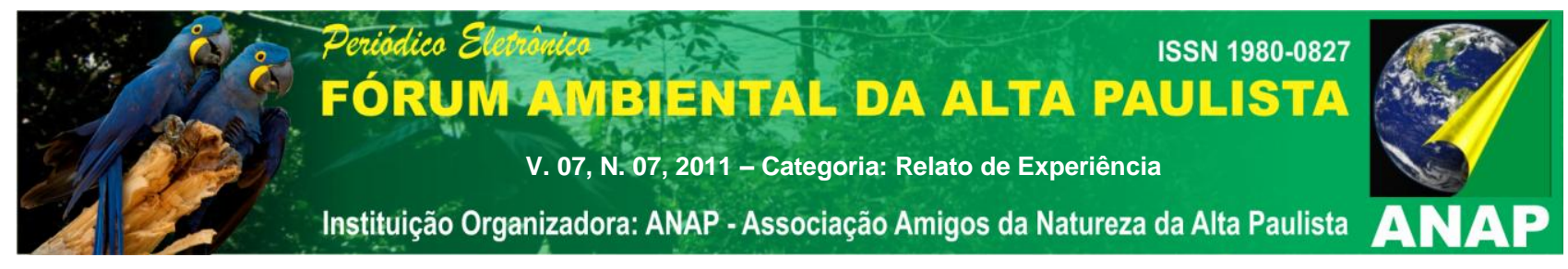

de Doutorado, Escola de Engenharia de São Carlos, Universidade de São Paulo, 2004. $137 p$. 